\title{
Study the Potential Nephro-protective Effect of Stem Cells Compared to Perindopril on Experimentally Induced Nephropathy
}

\author{
Ahmed M. Abd-Ella ${ }^{1, *}$ MSc, Hassan M. El-Kotby ${ }^{1}$ MD, Abd El-Lateef S. Abd El-Lateef ${ }^{1}$ MD, Wagih M. Abd \\ Elhai $^{2}$ MD
}

*Corresponding Author:

Ahmed M. Abd-Ella

ahmad.azhar.ph@gmail.com

Received for publication December 20, 2019; accepted January 24, 2020; published on line January 24, 2020.

Copyright 2020 The Authors published by Al-Azhar University, Faculty of Medicine, Cairo, Egypt. All rights reserved. This an openaccess article distributed under the legal terms, where it is permissible to download and share the work provided it is properly cited. The work cannot be changed in any way or used commercially.

doi:10.21608/aimj.2020.21241. 1028

${ }^{1}$ Pharmacology Department Faculty of Medicine, Al-Azhar University, Cairo Egypt.

${ }^{2}$ Histology Department Faculty of Medicine, Al-Azhar

University, Cairo Egypt.

\begin{abstract}
Background: Acute Kidney Injury (AKI) is as a public health problem worldwide. Gentamicin is one of the leading causes of drug-induced nephrotoxicity.

Objective: To assess the reno protective effect of ACEI Perindopril and BMDMCs on gentamicin induced nephrotoxicity in rats.

Material and Methods: The animals were divided into four groups: Group A (Control), Group B (Gentamicin-treated): It consists of 40 rats received sub-cutaneausly Gentamicin in a dose of $80 \mathrm{mg} / \mathrm{kg}$ once daily for 7 consecutive days and subdivided into 4 subgroups: B-I:10 rats as a control group. B-II: consists of 10 rats on the eighth day after Gentamicin injection they received oral Perindopril at doses of $6 \mathrm{mg} / \mathrm{kg}$ per day for4weeks. B-III: consists of10rats on the eighth day after Gentamicin injection, stem cells (MSC) were injected in tail vein at dose of $5 \times 10^{6}$ cells/rat. B-IV: consists of 10 rats on the eighth day after Gentamicin injection, stem cells (MSC) were injected in tail vein and oral Perindopril.

Results: Gentamicin induced kidney damage in rats was indicated by significant increase in the levels of serum urea, creatinine, potassium and tissue Malondialdehyde (MDA) concomitant with significant decrease in levels of serum sodium and tissue Super oxide dismutase (SOD) as compared to normal control group. Treatment with Perindopril significantly decreased serum urea and creatinine and significantly decreased tissue MDA. Treatment with BMSCs significantly decreased serum urea and creatinine, significantly increased serum sodium and decreased serum potassium and significantly decreased tissue MDA and increased tissue SOD.

Conclusions: These data indicate that treatment with stem cell in AKI can give better results than Perindopril and should encourage clinical studies to evaluate the potential benefit of MSC administration, because their infusion in humans is feasible and safe.
\end{abstract}

Keywords: $A K I$; $B M D M C S$; Perindopril

\section{INTRODUCTION}

Acute kidney injury is a common clinical problem, affecting approximately $5 \%$ to $10 \%$ of hospitalized patients and up to $60 \%$ of patients admitted to ICU. ${ }^{1}$ AKI may be linked to nephrotoxic drugs, infection, sepsis, renal ischemia, hypertension or inflammation. $^{2}$ Drugs cause approximately $20 \%$ of $\mathrm{AKI}^{3}$ Most drugs cause nephrotoxicity by alteration of intraglomerular hemodynamics, tubularcell toxicity, inflammation, crystal nephropathy, rhabdomyolysis and or thrombotic microangiopathy. ${ }^{4}$ Gentamicin is an effective aminoglycoside antibiotic but its associated adverse effects of oxidative stress and kidney injury limits its long-term clinical use. ${ }^{5}$

Authorship: All authors have a substantial
contributions to the article.
Disclosure: The authors have no financial
interest to declare in relation to the content of
this article. The Article Processing Charge was
paid for by the authors.

Serum creatinine and blood urea characteristically increase 7-10 days after initiation of aminoglycoside therapy. ${ }^{6}$ The incidence of aminoglycoside induced AKI is approximately $33 \%$ depending on therapy duration. $^{7}$

Gentamicin causes tubular damage through necrosis of tubular epithelial cells. ${ }^{8}$ In the proximal tubule, Gentamicin undergoes endocytosis and concentrates in lysosomes, Golgi body and endoplasmic reticulum. ${ }^{9}$ In cytoplasm Gentamicin acts on mitochondria ${ }^{10}$ and activates apoptosis pathway, decrease ATP synthesis and leads to oxidative stress resulting in cell death. ${ }^{11}$ Gentamicin has glomerular 
effects that alter filtration by producing mesangial contraction resulting in GFR reduction. ${ }^{12}$ Mesangial contraction could be mediated by PAF secretion which decreases GFR, activation of the renal RAS, production of vasoconstrictors as endothelin-1 and thromboxaneA2 andstimulation of CaSR. Renal cells express CaSR which mediates intracellular calcium mobilization. ${ }^{13}$ Raised intracellular $\mathrm{Ca} 2+$ activates calcium influx from the external source and $\mathrm{Ca} 2+$ release from the internal stores causing renal mesangial cellular contraction. ${ }^{14}$ Increase in ROS and oxidative stress which are able to damage many cellular molecules including proteins, lipids, and nucleic acids, contribute to mesangial and vascular contraction. $^{10}$

Gentamicin also blocks the synthesis of vasodilator prostaglandins. ${ }^{15}$ In the 1970 s, it was reported that angiotensin II had deleterious effects on the heart, vessels and kidney. Then came the discovery of drugs blocking the RAS, which clarified the role of this system in several pathologic conditions. ${ }^{16}$ Perindopril is a third generation ACE inhibitor that was developed for lowering blood pressure. ${ }^{17}$ Perindopril has many advantages as it possesses high bioavailability, high terminal elimination half-life of the major active ingredient, strong ACE inhibition, high lipophilicity and tissue penetration and prolonged duration of action $(>48 \mathrm{~h}){ }^{18}$

Stem cells with broad differentiation potential appear to exist in adult bone marrow and in other tissues as well. These various MSC share some common properties and surface phenotype but differ in their differentiation potential. ${ }^{19}$

Due to their plasticity, MSC are considered the most important cell type for regenerative medicine. Their advantages include the easy isolation, high plasticity, ability to modulate inflammation, promote cell growth, differentiation and tissue repair. MSC do not form teratomas after transplantation, ensuring safety to the host ${ }^{20}$ There are three minimal criteria for the definition of cultured MSCs: plastic adherent when maintained in standard culture conditions, expression of CD73, CD90, and CD105, and lack of CD14, CD 19 and CD45 and their tri lineage differentiation potential into adipocytes, chondrocytes and osteoblasts. $^{21}$

\section{MATERIAL AND METHODS}

Gentamicin sulphate was obtained from: E.I.P.I.Co. Perindopril arginine (Servier laboratories, Paris, France).Dulbecco's Modified Eagle's Medium (DMEM), fetal bovine serum (FBS) and Trypsin / EDTA $(0.25 \%)$. penicillin $/ \mathrm{ml}$ and streptomycin $/ \mathrm{ml}$ $100 \mathrm{IU} / \mathrm{ml}$ were supplied from LONZA -USA and stored at $4^{\circ} \mathrm{C}$ and $-70^{\circ} \mathrm{C}$.Phosphate buffered saline (PBS) was supplied from AWDIA -Egypt. Monoclonal antibody for CD34, CD44, and CD105 were used for characterization of mesenchymal stem cells.

50 Male Albino rats weighing (130 $\pm 20 \mathrm{gm})$ supplied from the animal house of Al-Nile Pharmaceutical Company. They were housed in stainless steel cages under a 12 hours light / dark cycle at room temperature. The doses of drugs were accurately calculated relative to the weight of each animal.

The animals were divided into two main groups:

Group A (Control group): consists of 10 rats received ordinary rat diet for 5 weeks, served as normal control group.

Group B (Gentamicin- treated group): consists of 40 rats received SC injected Gentamicin in a dose of 80 $\mathrm{mg} / \mathrm{kg}$ once daily for 7 consecutive days, ${ }^{22}$ subdivided into 4 subgroups 10 each.

Subgroup B-I: received no treatment as a control group.

Subgroup B-II: on the $8^{\text {th }}$ day after Gentamicin injection received oral Perindopril $6 \mathrm{mg} / \mathrm{kg}$ daily for 4 weeks.

Subgroup B-III: on the $8^{\text {th }}$ after Gentamicin injection MSC were injected in tail vein at dose of $5 \times 10^{6}$ cells/rat.

Subgroup B-IV: on the $8^{\text {th }}$ day of Gentamicin injection MSC were injected in tail vein at dose of $5 \times 10^{6}$ cells/rat and oral Perindopril at doses of 6 $\mathrm{mg} / \mathrm{kg}$ daily for 4 weeks.

\section{Ethics approval and consent to participate}

The current investigation was executed based on the recommendations of the ethical committee, Faculty of Medicine, Al-Azhar University, Cairo, Egypt.

Isolation of MSC: $:^{23-25}$

Ten male rats weighing 80-120 gm were anaesthetized by diethyl ether, the skin of both hind limbs was removed, the femurs and tibia were dissected from adherent soft tissues and placed into sterilized container containing DMEM. Dissection was performed in air laminar flow (UNAIR-USA). Both ends of each bone were cut, DMEM was flushed from one end of the bone and received in a falcon tube from the other end. Rat bone marrow was washed with sterile PBS for 5 minutes at $2000 \mathrm{rpm}$. Cells were washed twice.

\section{Primary culture of BMSCs:}

The final pellet was re-suspended in $10 \mathrm{ml}$ complete medium prepared as follow:- $89 \mathrm{ml}$ of DMEM, 10 $\mathrm{ml}$ of (FBS) and $1 \mathrm{ml}$ of Penicillin /streptomycin mixture. The cells were seeded in a $35 \mathrm{~mm}$ tissue culture dish at a density of $1 \times 10^{6}$ per flask in complete medium. The cells were incubated in a humidified atmosphere containing $5 \% \mathrm{CO}_{2}$, at $37^{\circ} \mathrm{C}$. Three days after seeding, the non-adherent cells were removed and the medium was replaced with a fresh complete medium. The culture was daily monitored using inverted microscope and the medium was changed every 3 days. After 10-14 days, cells were trypsinized. Cultures of rat MSCs were passaged twice a week and used at the $3^{\text {rd }}$ passage 3 .

\section{Characterization of MSC:}

Immunohistochemical processing was performed using monoclonal antibodies against rat $\mathrm{CD} 34$, CD44, and CD105 as follow:

MSC grown in $35 \mathrm{~mm}$ dishes were fixed by chilled acetone: methanol (1:1) for 10 minutes and washed 
twice with PBS. Sections were treated with $0.3 \%$ hydrogen peroxide in methanol $(30 \mathrm{~min})$ to abolish endogenous peroxidase. The cells were incubated for 30 minutes at room temperature with CD34, CD44 in PBS) then washed twice using PBS.

The cells were incubated with peroxidase conjugated rabbit anti-mouse $\operatorname{IgG}$ secondary antibody for 30 minutes at $37^{\circ} \mathrm{C}$ followed by incubation with $3,3-$ diaminobenzidine substrate staining for another 30 minute. Finally washed three times with PBS.

The cells were examined with phase contrast microscope and CD34, CD 44, and CD 105 reaction was observed by the bright field. Positive nuclear reactions appeared brown in color.

Cell survival at the beginning and end of the culture was determined by Trypan blue exclusion assay. ${ }^{6}$

Mesenchymal stem cells were suspended in $2 \mathrm{ml}$ of Hyaluronic acid solution at a density of $5 \times 10^{6}$ cells $/ \mathrm{ml}$ and were injected into the rat tail vein.

At the end of the study period, blood samples were collected from the epicanthus of the 14 hours fasting rats into blank tubes for determmation of serum urea, creatinine, sodium and potassium. The collected blood samples were kept till coagulation, and centrifuged at about $3000 \mathrm{rpm}$ for 15 minutes. Serum was collected into Ependorph tubes and kept at $-20^{\circ} \mathrm{C}$ till use.

\section{Histopathology}

All animals were sacrificed. Both kidneys were dissected out. The specimens were fixed in $10 \%$ Formal saline and processed to obtain paraffin blocks. Five um-thick sections were cut and stained with the Haematoxylin and Eosin stain (H\&E). and CD 105 monoclonal antibodies (1:200 dilutions

SOD and MDA were determined in kidney homogenate. ${ }^{11}$

\section{Statistical analysis of results:}

The variability of results was expressed as the mean \pm standard deviation $(X \pm S D)$. Statistical analysis of the difference between groups was performed by using (ANOVA) followed by Tukey's test as a post hoc analysis. Degree of significance: $\mathrm{P}>0.05=$ insignificant difference. $\mathrm{P}<0.05=$ significant difference.

\section{RESULTS}

The bone marrow cell culture on day one, revealed suspended cells with variable size. After 3 days, MSCs adhered to the to the flask substratum, showing a small population of single cells. The cells became spindle shaped, with single nucleus on day seven, the cells were heterogeneous; some were rounded and of hematopoietic origin (non-adherent floating cells), whereas others were long, spindle shaped, with a fibroblast-like appearance, and began to form colonies.

The rat BMSCs in subculture appeared mostly spindle in shape, with granular cytoplasm and vesicular nucleus. MSCs were polygonal or spindle shaped, with long processes after re-plating during the second and third passages. They showed a single phenotypic population at these passages. All the samples were similar with regard to the colony formation and cellular morphology.

\section{Characterization of MSCs}

Immunohistochemical characterization was performed on a monolayer of expanded rat MSCs of the third passage. These cells were mostly positive for CD44 and CD105. MSCs had a brown cytoplasmic staining. In contrast, rat MSCs were almost negative for CD34.

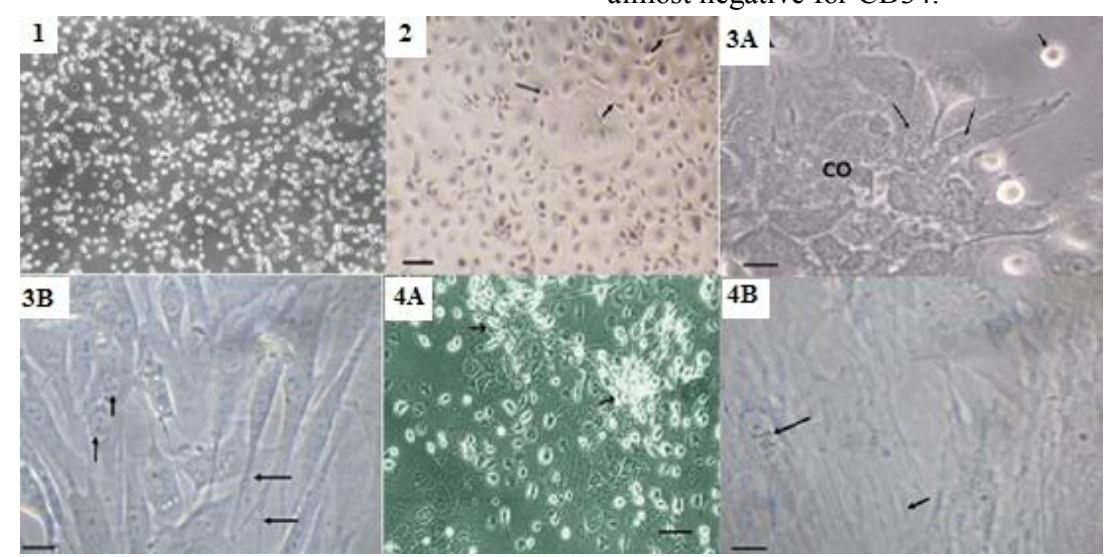

Fig. 1: BM-MSCs on dayl of primary culture showed non-adherent rounded cells with variable size.(100x 200) Fig. 2: Spindle shaped(short arrow), Another cells appeared floated and rounded (long arrow) (P0x 200). (100 $\mu \mathrm{m}$. X100)

Fig. 3A: floating cells are seen (short arrow) and other spindle-shaped cells with granular cytoplasm, large

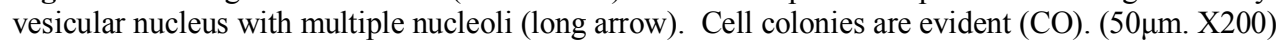

Fig. 3B: The cells are polygonal to fibroblast-like showing granular cytoplasm with single nucleus and multiple

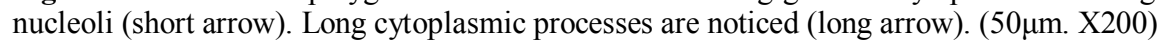

Fig. 4 A: The cells are shown as colonies of closely opposing cells and they take different morphological appearance. $(100 \mu \mathrm{m}$. X100)

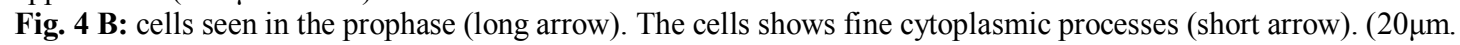
$\mathrm{X} 400)$ 



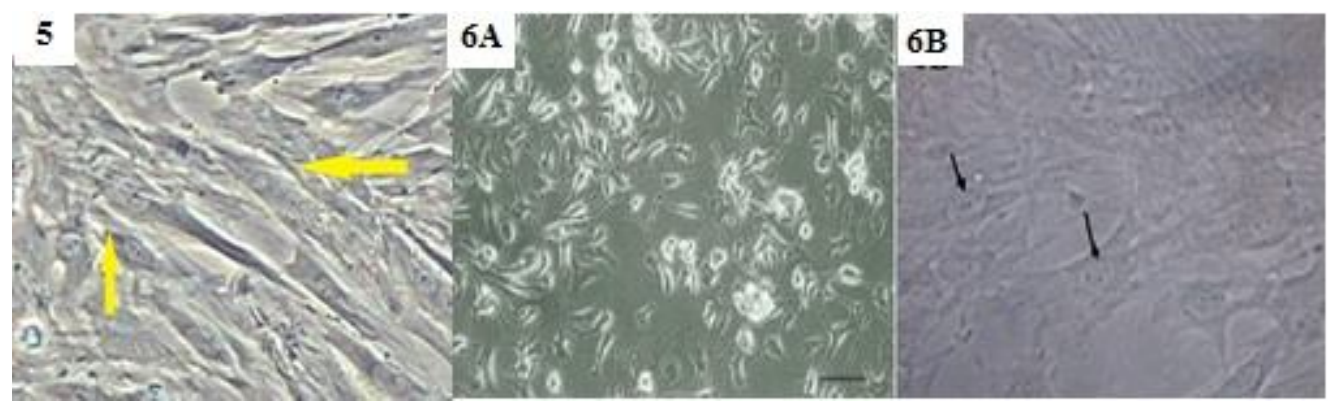

Fig. 5: First-passaged BM-MSCs (P1). Most cells are spindle $(\uparrow)$ in shape with long cytoplasmic processes having granular cytoplasm with vesicular nuclei. Scalebar $20 \mu \mathrm{m} . \mathrm{x} 200$

Fig. 6A: BM-MSCs during the $3^{\text {rd }}$ passage. $(100 \mu \mathrm{m}$. X100)

Fig. 6B: Primary cultured MSC 2 week after culture. The cells are approximately $70-75 \%$ confluent, showing cells with granular cytoplasm, large vesicular nucleus with multiple nucleoli $(\uparrow) .(50 \mu \mathrm{m} . \mathrm{X} 200)$

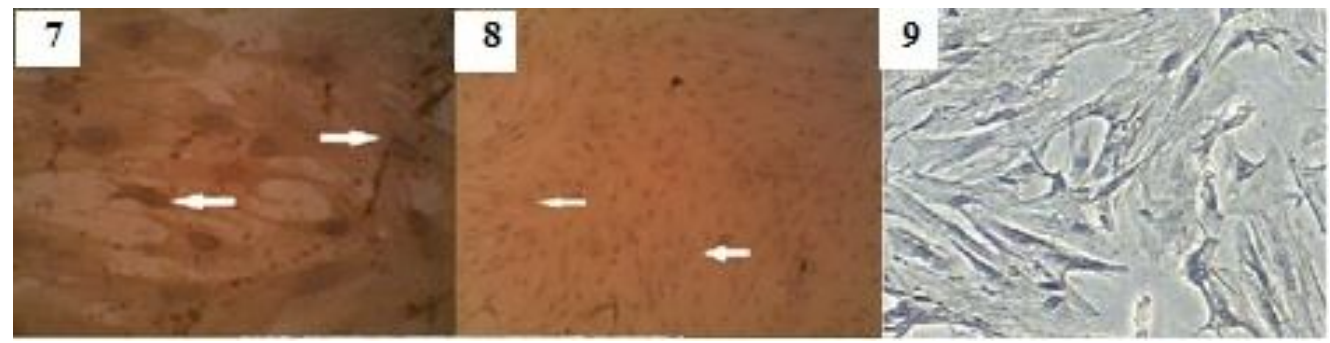

Fig. 7: $3^{\text {rd }}$ passaged BM-MSCs with positive brownish immune reaction for CD 105 in the cytoplasm and cell processes $(\uparrow)$. Avidine-biotin Peroxidase for CD105. ( $50 \mu \mathrm{m}$. X200)

Fig. 8: $3^{\text {rd }}$ passaged BM-MSCs with positive brownish immune reaction for anti CD44 antibody. Avidine-biotin Peroxidase for CD44. ( $50 \mu \mathrm{m}$. X200)

Fig. 9: $3^{\text {rd }}$ passaged BM-MSCs with negative cytoplasmic immune reaction for anti CD 34 antibody. Avidin-biotin Peroxidase for CD34. ( $50 \mu \mathrm{m}$. X200)

\section{Biochemical assay}

Renal Function: The mean value of blood urea in group A was $26.8 \pm 3.7 \mathrm{mg} / \mathrm{dl}$, in BI was $84.17 \pm 3.59$ $\mathrm{mg} / \mathrm{dl}$, in group BII was $52.37 \pm 9.6 \mathrm{mg} / \mathrm{dl}$, in group BIII was $40.1 \pm 6.9 \mathrm{mg} / \mathrm{dl}$ and in group BIV was $36.52 \pm 7.4 \mathrm{mg} / \mathrm{dl}$.

It is found that blood urea level significantly elevated post administration of Gentamicin compared with normal control group A $(\mathrm{P}<0.05)$. In the same time there was a significant decrease post treatment with Perindopril, MSC, MSC - perindopril $(\mathrm{P}<0.05)$ respectively compared with groupBI $(\mathrm{P}<0.05)$. In group BIII and in group BIV there was a significant decrease as compared to group BII $(\mathrm{P}<0.05)$.

The mean of serum creatinine level in group A was $0.86 \pm 0.19 \mathrm{mg} / \mathrm{dl}$, in group BI was $2.9 \pm 0.52 \mathrm{mg} / \mathrm{dl}$, in group BII was $2 \pm 0.39 \mathrm{mg} / \mathrm{dl}$, in group BIII was $0.98 \pm 0.33 \mathrm{mg} / \mathrm{dl}$ and in group BIV was $0.96 \pm 0.28$ $\mathrm{mg} / \mathrm{dl}$.

It is found that serum creatinine level significantly elevated post administration of Gentamicin compared with normal control groupA $(\mathrm{P}<0.05)$. In the same time there was a significant decrease post treatment with Perindopril, MSC, MSC - perindopril $(\mathrm{P}<0.05)$ respectively compared with group $\mathrm{BI}(\mathrm{P}<0.05)$. In group BIII and group B IV there was a significant decrease as compared to BII $(\mathrm{P}<0.05)$.

Serum Electrolytes: The mean of serum sodium level in group Awas $131 \pm 5.5 \mathrm{mg} / \mathrm{dl}$,in group BI was $112.6 \pm 7.9 \mathrm{mg} / \mathrm{dl}$, in group BII was $119 \pm 3.2 \mathrm{mg} / \mathrm{dl}$, in group BIII was $130.3 \pm 6.4 \mathrm{mg} / \mathrm{dl}$ and in group BIV was $129.3 \pm 10.7 \mathrm{mg} / \mathrm{dl}$.It is found that serum sodium level significantly decreased post administration of Gentamicin compared with normal control groupA $(\mathrm{P}<0.05)$. In the same time there was a significant increase post treatment with Perindopril, MSC, MSC - perindopril $(\mathrm{P}<0.05)$ respectively compared with group $\mathrm{BI}(\mathrm{P}<0.05)$. In group $\mathrm{BIII}$ and in group $\mathrm{BIV}$ there was a significant increase as compared to group BII $(\mathrm{P}<0.05)$.

Also, the mean of serum potassium level in group A was $3.81 \pm 0.55 \mathrm{mg} / \mathrm{dl}$, in group BI was $5.31 \pm 0.86$ $\mathrm{mg} / \mathrm{dl}$, in group BII was $5.6 \pm 0.8 \mathrm{mg} / \mathrm{dl}$, in group BIII was $4.51 \pm 0.76 \mathrm{mg} / \mathrm{dl}$ and in BIV was $4.33 \pm 0.76$ $\mathrm{mg} / \mathrm{dl}$. It is found that serum potassium level significantly elevated post administration of Gentamicin compared with normal control groupA $(\mathrm{P}<0.05)$. In the same time there was a significant decrease post treatment with MSC, MSC perindopril $(\mathrm{P}<0.05)$ respectively compared with group $\mathrm{BI}(\mathrm{P}<0.05)$. In group BIII and in group BIV there was a significant decrease as compared to group BII $(\mathrm{P}<0.05)$. 


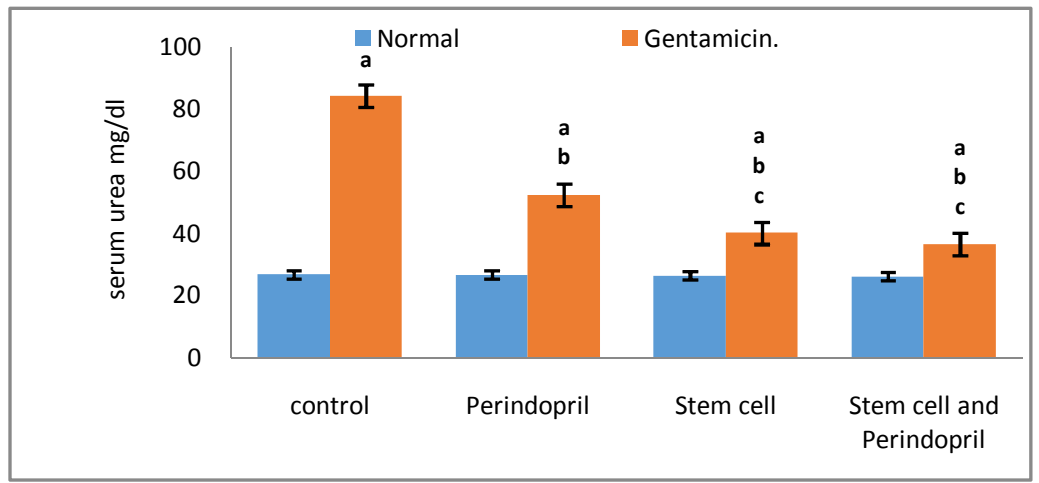

Fig. 10: Assessment of serum urea (mg/dl), in treated groups. Values indicate mean \pm SD.

a Significant increase from normal control group.

b Significant decrease from Gentamicin treated group.

c Significant decrease from Gentamicin and Perindopril medicated group.

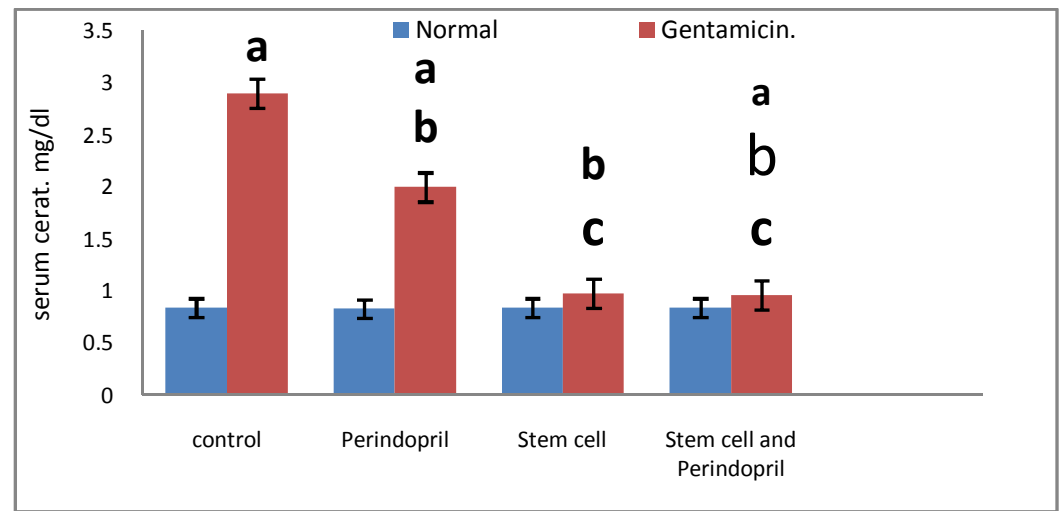

Fig.11: Assessment of serum creatinine ( $\mathrm{mg} / \mathrm{dl})$, in treated groups. Values indicate mean $\pm \mathrm{SD}$.

a Significant increase from normal control group.

b Significant decrease from Gentamicin treated group.

c Significant decrease from Gentamicin and Perindopril medicated group.

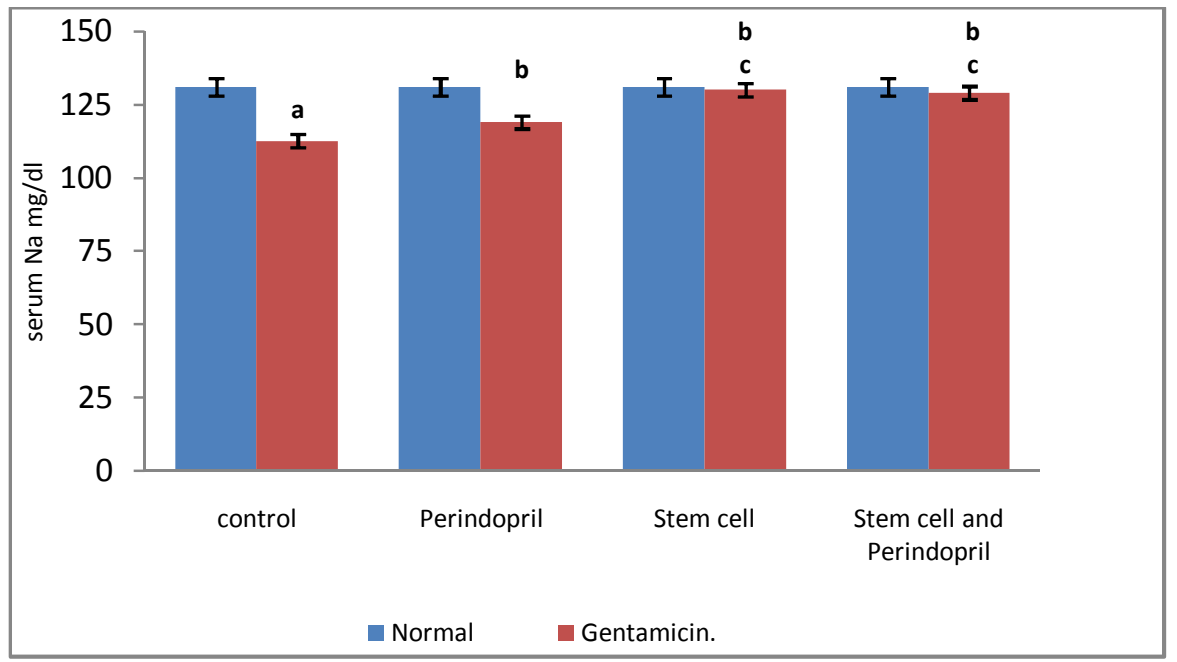

Fig. 12: Assessment of serum sodium (mg/dl), in treated groups. Values indicate mean $\pm \mathrm{SD}$.

a Significant decrease from normal control group.

b Significant increase from Gentamicin treated group.

c Significant increase from Gentamicin and Perindopril medicated group. 


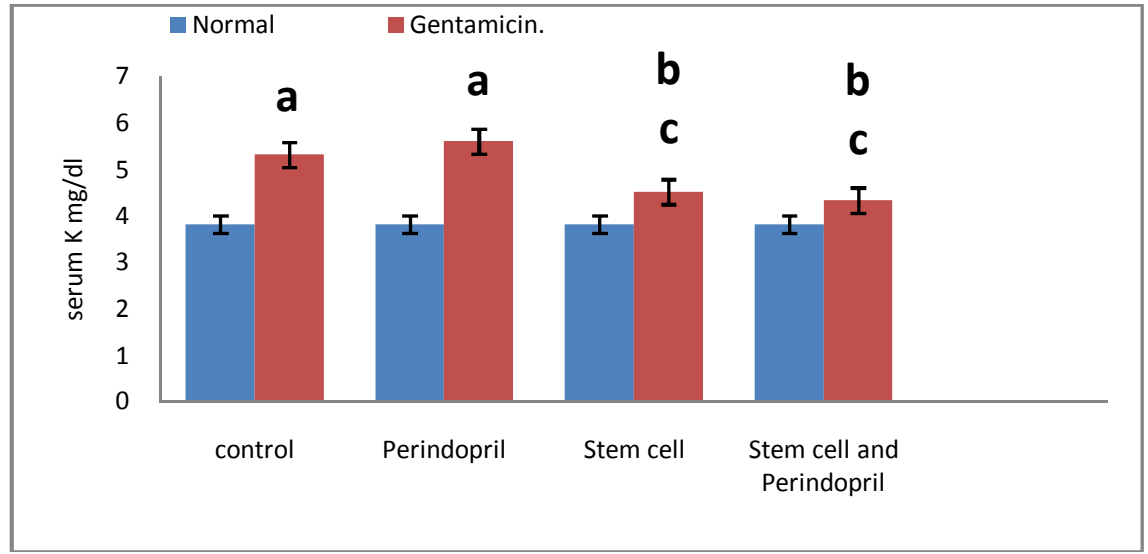

Fig. 13: Assessmentof serum potassium $(\mathrm{mg} / \mathrm{dl})$, in treated groups. Values indicate mean \pm SD.

a Significant increase from normal control group.

b Significant decrease from Gentamicin treated group.

c Significant decrease from Gentamicin and Perindopril medicated group.

MDA in kidney tissue homogenatelevel in group A was $0.75 \pm 0.13 \mathrm{nmol} / \mathrm{mg}$ tissue, in group BI was 0.97 $\pm 0.23 \mathrm{nmol} / \mathrm{mg}$ tissue, in group BII was $0.89 \pm 0.3$ $\mathrm{nmol} / \mathrm{mg}$ tissue, in group BIII was $0.80 \pm 0.2$ $\mathrm{nmol} / \mathrm{mg}$ tissue and in group BIV was $0.77 \pm 0.3$ $\mathrm{nmol} / \mathrm{mg}$ tissue.It is found that tissue MDA level significantly elevated post administration of Gentamicin compared with control group A $(\mathrm{P}<0.05)$. In the same time there was a significant decrease post treatment with Perindopril, MSC, MSC - perindopril $(\mathrm{P}<0.05)$ respectively compared with group BI $(\mathrm{P}<0.05)$. In group BIII and in group BIV there was a significant decrease as compared to group BII $(\mathrm{P}<0.05)$.

Finally SOD in kidney tissue homogenate level in group Awas 78.4 $\pm 4.3 \mathrm{U} / \mathrm{mg}$ tissue, in group BI was
$39.2 \pm 3.2 \mathrm{U} / \mathrm{mg}$ tissue, in group BII was $46.8 \pm 5.9$ $\mathrm{U} / \mathrm{mg}$ tissue, in group BIII was $70.5 \pm 6.8 \mathrm{U} / \mathrm{mg}$ tissue and in group BIV was $73 \pm 4.1 \mathrm{U} / \mathrm{mg}$ tissue.It is found that tissue SOD level significantly decreased post administration of Gentamicin compared with normal control group $\mathrm{A}(\mathrm{P}<0.05)$. In the same time there was a significant increase post treatment with MSC, MSC - perindopril $(\mathrm{P}<0.05)$ respectively compared with group $\mathrm{BI}(\mathrm{P}<0.05)$. In group $\mathrm{BIII}$ and in group $\mathrm{BIV}$ there was a significant increase as compared to group BII $(\mathrm{P}<0.05)$.

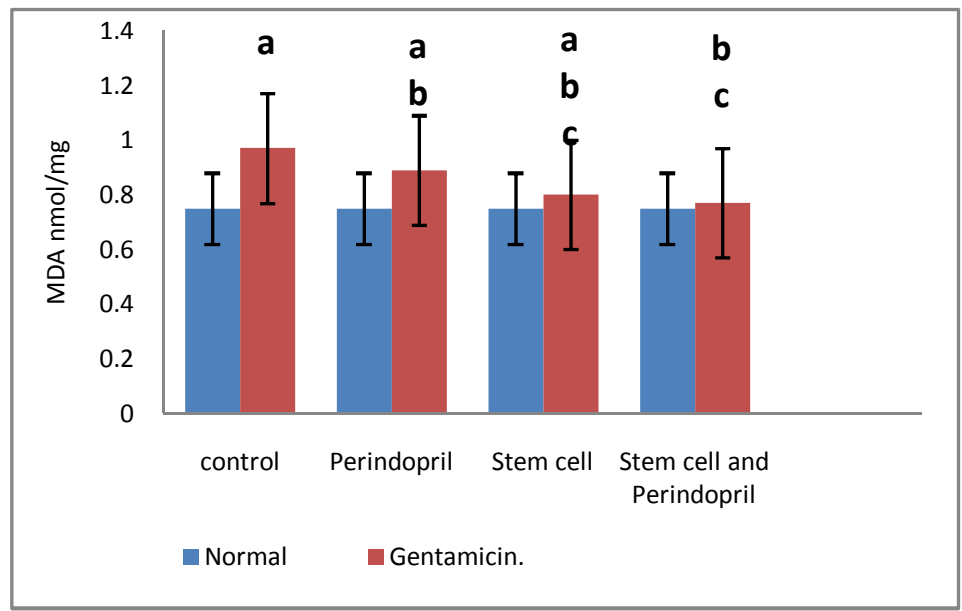

Fig. 14: Assessmentof(MDAnmol/mg tissue), in treated groups. Values indicate mean \pm SD.

a Significant increase from normal control group.

b Significant decrease from Gentamicin treated group.

c Significant decrease from Gentamicinand Perindopril medicated group. 


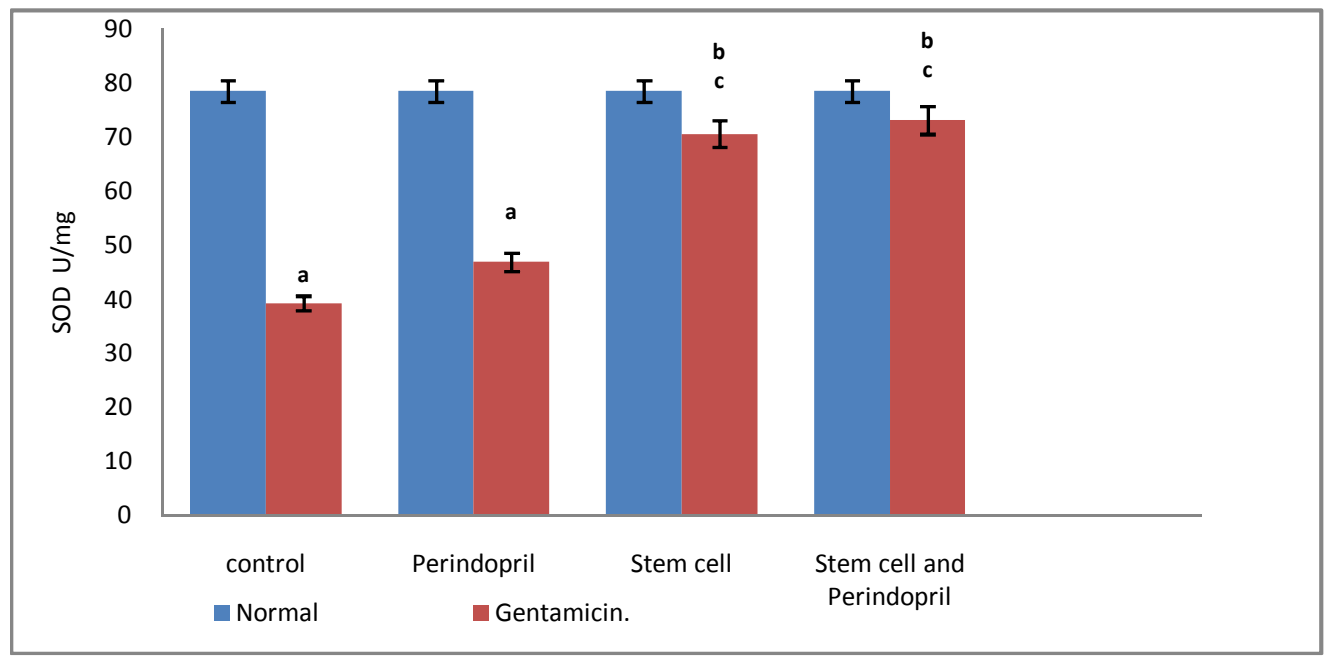

Fig. 15: Assessment of (SODU/mg)in treated groups. Values indicate mean \pm SD.

a Significant decrease from normal control group.

b Significant increase from Gentamicin treated group.

c Significant increase from Gentamicin and Perindopril medicated group.

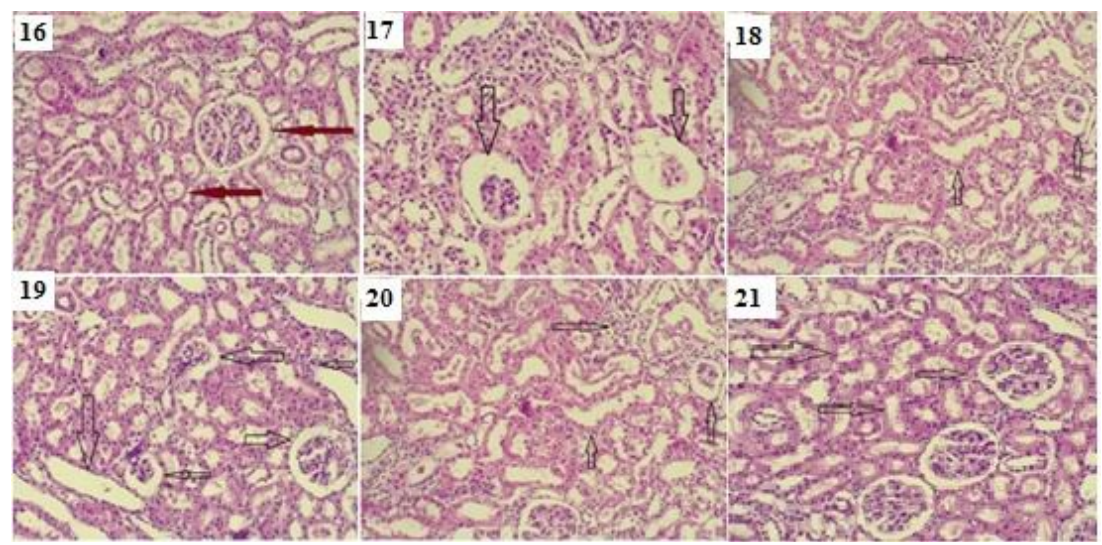

Fig. 16: A photomicrograph of a section of the renal cortex of control group showing normal renal corpuscles and closely packed renal tubules. Renal corpuscles formed of a glomerulus surrounded by Bowman's capsule. The PCTs have narrow lumen and are lined with cubical cells with dark acidophilic cytoplasm. The DCTs have wider lumen and are lined with cubical cells with less acidophilic cytoplasm. (H\&E x 200)

Fig. 17: Photomicrograph of kidney section of rat with Gentamicin nephropathy showing epithelial necrosis, degeneration and dilation of Bowman's space . (H\&E. x200)

Fig. 18: Photomicrograph of kidney section of rat with Gentamicin nephropathy showing dilatation and necrosis in the kidney tubules with it ratubular inflammatory cell infiltration and collapsed glomeruli. (H\&E. x200)

Fig. 19: Photomicrograph of kidney section of rat with Gentamicin nephropathy treated by Perindopril showing some improvement of glomerular changes, some tubules remained dilated with mild inflammatory cell infiltration. (H\&E. x200)

Fig. 20: Photomicrograph of kidney section of rat with Gentamicin nephropathy treated by BMD-MCS showing closely packed tubules and apparent normal structure of renal corpuscle, tubules and blood vessels. (H\&E. x200)

Fig. 21: Photomicrograph of kidney section of rat with Gentamicin nephropathy treated by BMD-MCS and Perindopril showing closely packed tubules and apparent normal structure of renal corpuscle, tubules. (H\&E. $\mathrm{x} 200)$ 


\section{DISCUSSION}

The most common cause of AKI is exposure to nephrotoxic agents that lead to acute tubular necrosis. ${ }^{26}$ AKI is a major cause of morbidity and mortality in hospitalized patients. ${ }^{27}$ Aminoglycosides are widely used in the treatment of a variety of infections produced by Gram negative bacteria. ${ }^{28}$ Several investigators reported that Gentamicin produces nephrotoxicity, evident by an increase in BUN and serum creatinine levels. ${ }^{29}$ Ang II is reported as an important factor in Gentamicin induced AKI. Ang II has pro-oxidative, vasoconstrictive effects and causes hypo-perfusion, and it is the reason that (ACE) blocking has protectively important role for the kidney. ${ }^{30}$

Gentamicin produces oxidative stress in tubular cells, both in vivo and in cultured tubular cells ${ }^{32}$ Gentamicin induced nephrotoxicity was associated with increase in tissue MDA level that indicated lipid peroxidation and low SOD activities. ${ }^{33}$ In the present study, Gentamicin injection in rats caused nephrotoxicity, indicated by significant increase in blood urea and serum creatinine, potassium and tissue (MDA) concomitant with significant decrease in serum sodium and tissue SOD as compared to normal control group that was in agreement I'hsan and Engin $2010^{34}$, Gehan $2011^{35}$ and Abdelrahman $2018 .^{36}$

The elevated serum creatinine level is the most powerful indicator in the first phases of kidney disease while blood urea starts to increase only after parenchymal injury. ${ }^{37}$ Lower values of serum sodium indicates inability of kidney to conserve sodium. Haemodilution may be involved in the fall of sodium value via excess water intake and/or increase production of endogenous water, in turn; the reversed increases of potassium appeared to be due to reduced excretion of $\mathrm{K}+$ aggravated by leakage of intracellular potassium into blood. ${ }^{38}$ These results are in harmony with the data obtained by Hala $2012 .{ }^{39}$

Potential nephron protective effects of (RAS) inhibitors in drug induced nephrotoxicity have been documented in several studies. ${ }^{40}$ The use of ACEi and ARBs has significantly changed the incidence of ESRD through their effects on RAS, hemodynamic changes, and other pleiotropic effects that include anti-inflammatory, antioxidant and antithrombotic effects. Although this therapy carries a significant risk of hyperkalemia So, other therapies aiming at decreasing serum potassium levels should be considered before discontinuing RAS blockers in cases of mild/non-life-threatening hyperkalemia. ${ }^{41}$ In the lack of effective therapies, stem cell has recently emerged as a promising treatment trial for AKI. With their plasticity, BM-MSCs have been extensively studied due to their potential to enhance recovery of the injured cells. ${ }^{42}$ Different types of stem cellscan stimulate renal repair in vivo in models of kidney failure. ${ }^{43}$ BM-MSCs are multipotent with immunomodulatory ability, capacity for expanding easily in vitro and the potential for differentiation into cells of mesenchymal or other lineage. Such properties have made BM-MSCs an attractive candidate for stem cell-based therapy. ${ }^{44}$ MSC have been described as one of the most efficient cell populations for activating the regeneration of the damaged kidney. ${ }^{45}$ Certain studies have reported that exogenous BMMSCs can engraft into injured tubules and proposed that the ability of the BM-MSCs to transdifferentiate explains their protective effects. ${ }^{46,47}$ In contrast with other studies have shown that BM-MSCs protect against acute tubular injury through a differentiationindependent process. ${ }^{48,49}$

Moreover, improvements of injured tissues take place rapidly to be explained by differentiation of MSCs. ${ }^{50}$ Pengfei results have indicated that MSCs could migrate into kidney tissue but most cells are located in blood vessel or adhere on blood vessel wall in kidney, and few MSCs could join into kidney tissue repair or regeneration. Therefore, whether MSCs can differentiate into renal cells and further repair the damaged tissue still needs our further exploration in AKI model.$^{51}$ Different cells interact together to enable the kidneys to fulfill their physiological role; MSCs can differentiate, regenerate and/or protect mesangial cells, tubular epithelial cells, endothelial cells and podocytes. ${ }^{52}$ MSC secrete a number of factors, including VEGF, HGF, IGF-1, FGF and SDF-1, that exert antiapoptotic, mitogenic, vasoprotective, and angiogenic actions in AKI. Recently, several groups have demonstrated the potent therapeutic activity of microvesicles (MVs), termed as exosomes and shedding vesicles. ${ }^{53}$

Micro-Vesicles are released from stem cells and are enriched in adhesion molecules, membrane trafficking molecules, cytoskeleton molecules, heatshock proteins, cytoplasmic enzymes, mRNAs and microRNAs. Their role in vivo may be related to cell-to cell communication and to proteins and RNAs exchange among cells both locally and at distance. ${ }^{54}$ Several studies have suggested that stem cell-derived EVs may play an emerging role as an alternative therapeutic approach to tissue regeneration. ${ }^{55}$ Treatment using Perindopril and stem cell logically improved the outcome of therapy though not statically significant as compared to stem cell alone therapy.

\section{CONCLUSION}

Kidney disease is a major cause of morbidity and mortality worldwide Treatment with Perindopril can partially improve renal function although it is associated with hyperkalemia. Stem cell therapy notably improved renal function in AKI model with improvement of serum electrolyte (sodium and potassium), oxidative stress parameters. Stem cell based therapeutic potential is a promising research field and the results presented here should encourage clinical studies to evaluate the potential benefit of MSC administration. However, long-term monitoring is recommended to rule out the potential risk of cancer and of developing anti-HLA antibodies.

\section{REFERENCES}

1- Peter M, Raymond $\mathrm{H}$ and Kathleen L. Management of Acute Kidney Injury. Core 
Curriculum 2018. Am J Kidney Dis.2018; 72(1): 13648.

2- Endre ZH. and Pickering JW. Acute kidney injury: cell cycle arrest biomarkers win race for AKI diagnosis. Nat Rev Nephro.2014; 10: 683-85.

3- Kohli HS, Bhaskaran MC and Muthukumar T. Treatment-related acute renal failure in the elderly: a hospital-based prospective study. Nephrol Dial Transplant.2000;15(2):212-17.

4- Schetz M, Dasta J, Goldstein S, et al. Druginduced acute kidney injury. Curr Opin Crit Care.2005;11(6):555-65.

5- Ali B, Al Záabi M, Blunden G. et al. A. Experimental gentamicin nephrotoxicity and agents that modify it: a mini-review of recent research. Basic Clin. Pharmacol. Toxicol.2011; 9: 225-32.

6- Sandhu JS, Sehgal A., Gupta O, et al. Aminoglycoside nephrotoxicity revisited, JIACM.2007; 8 (4);331-33.

7- Ong LZ, Tambyah PA and Lum LH. Aminoglycoside associated acute kidney injury in elderly patients with and without shock. Jour. Antimicrob Chemother. 2016; 71: 3250-57.

8-Pavle R, Slavimir V, Nenad S, et al. Gentamicin nephrotoxicity in animals:current knowledge and future Pprespectives. EXCLI Journal.2017;16: 38899.

9- Kurt A. Wargo and Jonathan D. Edwards. Aminoglycoside-Induced Nephrotoxicity. Journal of Pharmacy Practice.2014; 27(6) :573-77.

10- Morales AI, Detaille D. and Prieto M. Metformin prevents experimental gentamicin-induced nephropathy by a mitochondria-dependent pathway. Kidney Int.2010; 77: 861-69.

11- Cuzzocrea S, Mazzon E, Dugo L, et al. A role for superoxide in Gentamicin mediated nephropathy in rats. Eur. Jour. Pharmacol.2002; 450:67-76.

12- Martinez C, Lopez F and Lopez J. Glomerular nephrotoxicity of aminoglycosides. Toxicol Appl Pharmacol.2007; 223:86-98.

13- Martinez C, Rodriguez A., Tavares P., et al., Role of calcium in gentamicin- induced mesangial cell activation. Cell PhysiolBiochem.2000; 1: 65-72.

14- Balakumar P, Rohilla A and Thangathirupathi A. Gentamicin-induced nephrotoxicity: Do we have a promising therapeutic approach to blunt it? Pharmacol. Res.2010; 62: 179-86.

15- Jose M, Lopez N, Yaremi Q, et al. New insights into the mechanism of aminoglycoside nephrotoxicity: an integrative point of view. International Society of Nephrology.2011; 79: 33-45.

16- Fox K. Management of coronary artery disease: implications of the EUROPA trial. $\mathrm{Br} J$ Cardiol.2004;11:195-204.
17- Hanif K, Bid H and Konwar R. Reinventing the ACE inhibitors: Some old and new implications of ACE inhibition. Hypertens. Res.2010; 33: 11-21.

18- Valentina B, Minodora A, Adriana L, et al. Comparative Solid-State Stability of Perindopril Active Substance vs. Pharmaceutical FormulationInt. Jour. Mol. Sci.2017; 18: 164-79.

19- Wagner W, Wein F, Seckinger A, et al. Comparative characteristics of mesenchymal stem cells from human bone marrow, adipose tissue, and umbilical cord blood. ExpHematol.2005; 33: 140216.

20- Insausti L, Blanquer M, García $\mathrm{M}$, et al. Amniotic membrane-derived stem cells: immunomodulatory properties and potential clinical application. Stem Cells Cloning.2014;7:53-63.

21- Kuroda Y, Kitada $\mathrm{M}$ and Wakao S. Bone Marrow Mesenchymal Cells: How Do They Contribute to Tissue Repair and Are They Really Stem Cells? Arch. ImmunolTherExp.2011; 59: 36978 .

22- Joel D, Annamaria L, Bela I, et al. L-carnitine ameliorates gentamicin induced renal injury in rats. Nephrol Dial. Transplant.2002; 17:2122-31.

23- Sangeetha P, Maiti K, Divya $M$, et al. Mesenchymal Stem Cells Derived from Rat Bone Marrow (rBM MSC): Techniques for Isolation, Expansion and Differentiation. J. Stem Cell Res Ther.2017;3(3): 101- 09.

24- Tahani M, Mohamed A, Reda E, et al. Therapeutic Effects of Bone Marrow Stem Cells in Diabetic Rats. J. of Computer Science \& Systems Biology.2016; 9:58-68.

25- Wakitani S, Saito T and Caplan I. Myogenic cells derived from rat bone marrow mesenchymal stem cells exposed to 5-azacytidine. Muscle Nerve.1995; 18:1417-26.

26- Jordi R, Fritz D, Josep M, et al. Therapeutic application of extracellular vesicles in acute and chronic renal injury. Nephrologia.2017;37(2):12637.

27- Bellomo R, Kellum A and Ronco C. Acute kidney injury. Lancet.2012;380:756-66.

28- Chen F. and Kaye D. Current use for old antibacterial agents: polymyxins, rifamycins, and aminoglycosides. Infect Dis Clin North Am. 2009; 23:1053-75.

29- Atessahin A, Karahan I, Yilmaz S, et al. The effect of manganese chloride on gentamicin-induced nephrotoxicity in rats.Pharmacol.Res. 2003 ; 48: 63742 .

30- Milan Ć, Mirjana R, Milkica N, et al. The effects of enalapril on experimental Gentamicin nephrotoxicity. Acta Medica Medianae.2014;53:1621. 
31- Karatasx Y, Secxilmisx A, Karayaylali I, et al. Effect of tempol (4-hydroxy tempo) on gentamicininduced nephrotoxicity in rats. Fundam.Clin.Pharmacol.2004; 18: 79-83.

32- Juan $H$, Chen $H$, Hsu $H$, et al. Tetramethylpyrazine protects rat renal tubular cell apoptosis induced by gentamicin. Nephrol. Dial. Transplant. 2007; 22: 732-739.

33- Lopez M., Quiros Y, Vicente L, et al. New insights into the mechanism of aminoglycoside nephrotoxicity: an integrative point of view. Kidney Int.2011; 79: 33-45.

34- I'hsan $Y$ and Engin B. Protective effects of nigella sativa against gentamicin-induced nephrotoxicity in rats. Experimental and ToxicologicPathology.2010; 62:183-90.

35- Gehan H. Angiotensin II Receptor Blocker, Losartan, Ameliorates Gentamicin-Induced Oxidative Stress and Nephrotoxicity in Rats. Pharmacology.2011;87:232-40.

36- Abdelrahman S. Protective effect of apocynin against gentamicin-induced nephrotoxicity in rats. Human and Exp. Toxicology.2018; 37: 27-37.

37- Kalayarasan S, Prabhu N, Manikandan R, et al. Diallyl sulfide enhances antioxidants and inhibits inflammation through the activation of Nrf2 against gentamicin-induced nephrotoxicity in Wistar rats, Eur. J. Pharmacol.2009; 606 : 162-71.

38- Padmini P and Kumar V. A histopathological study on gentamicin induced nephrotoxicity in experimental albino rats. Jour. of Dental and Med. Sci.2012; 1(1):14-17.

39- Hala K. Effect of Morin against GentamicinInduced Nephrotoxicity in Young Male Rats.The Egyptian Journal of Hospital Medicine.2012; 49: 705- 17.

40- Heeba H. Angiotensin II receptor blocker, losartan, ameliorates gentamicin-induced oxidative stress and nephrotoxicity in rats. Pharmacology.2011; 87: 232-40.

41- Rabi Y and Kirk C. Inhibition of RAS in diabetic nephropathy. Intern. Jour. of Neph. and Renovascular Dis.2015;8:29-40.

42- Rokaya S, Laila R, Alaa I, et al. Hematopoietic stem cells derived from human umbilical cord ameliorate cisplatin-induced acute renal failure in rats. Am Jour. Stem Cells.2014; 3(2): 83-96.

43- Julia M, Benedetta B, Marie C, et al. Concise Reviews: Stem Cells and Kidney Regeneration: An Update. Stem Cells TM.2019; 8:82-92.

44- Shaohua I and Dongcheng U. Bone marrowderived mesenchymal stem cells protect against cisplatin-induced acute kidney injury in rats by inhibiting cell apoptosis. Inter. J. Of Molec. Med.2013; 32: 1262-72.
45- Cinzia R, Marina M and Barbara I. Stem Cell Therapies in Kidney Diseases: Progress and Challenges. Int. J. Mol. Sci.2019;20: 2790-816.

46- Herrera B, Bussolati B, Bruno S, et al. Mesenchymal stem cells contribute to the renal repair of acute tubular epithelial injury. Int $J \mathrm{Mol}$ Med.2004; 14: 1035- 41.

47- Yokoo $\mathrm{T}$, Ohashi $\mathrm{T}$ and Shen $\mathrm{S}$. Human mesenchymal stem cells in rodent whole-embryo culture are reprogrammed to contribute to kidney tissues. Proc Natl Acad Sci.2005; 102: 3296-3300.

48- Tögel F, Hu Z, Weiss $\mathrm{K}$, et al. Administered mesenchymal stem cells protect against ischemic acute renal failure through differentiationindependent mechanisms. Am $J$ Physiol Renal Physiol.2005; 289: 31-42.

49- Mohamed A, Mohamed W, Hanan A, et al. The role of bone marrow derived-mesenchymal stem cells in attenuation of kidney function in rats with diabetic nephropathy. Diabetology\& Metabolic Syndrome.2014; 6:34.

50- Azam A, Mahnaz A, Mansor J, et al. Effect of Different Times of Intraperitoneal Injections of Human Bone Marrow Mesenchymal Stem Cell Conditioned Medium on Gentamicin-Induced Acute Kidney Injury. Miscellaneus.2016; 13: 2707- 2716.

51- Pengfei L, Yetong F, Delu D, et al. Enhanced renoprotective effect of IGF-1 modified human umbilical cord-derived mesenchymal stem cells ongentamicin-induced acute kidney injury. Scientific Reports.2016; 6:20287p114.

52- Marcelo E, Martha A, Maximiliano G, et al. Mesenchymal Stem Cell Therapy in Type 1 Diabetes Mellitus and Its Main Complications: From Experimental Findings to Clinical Practice. J Stem Cell Res Ther.2014; 4:8.

53- Francesca B, Elisa S, Chiara D, et al. Potential advantages of acute kidney injury management by mesenchymal stem cells. World J Stem Cells.2014; 26; 6(5): 644-50.

54- Camussi G, Deregibus MC and Cantaluppi V. Role of stem-cell derived microvesicles in the paracrine action of stem cells. Biochem Soc Trans.2013;41: 283-87.

55- Grange C, Iampietro C and Bussolati B. Stem cell extracellular vesicles and kidney injury. Stem cell Investig. 2017; 4: 90. 